\title{
Webinar as the Future Educational Tool in Higher Education of India: A Survey-Based Study
}

\author{
Sanjib Kumar Gupta ${ }^{1}$ (D) Nabanita Sengupta ${ }^{1}$
}

Accepted: 7 January 2021 / Published online: 17 January 2021

(c) The Author(s), under exclusive licence to Springer Nature B.V. part of Springer Nature 2021

\begin{abstract}
In contemporary times online learning process has become indispensable for higher education in India. The common practice of chalk and talk method is no longer the only recommended method of pedagogy. As a result, blackboards are gradually being replaced by digital smart boards and LCD screens which allow both traditional and technological modes of teaching. Government of India also realises the immense potential that such technologies have. In this direction, 'Digital India' is a one step forward initiative of the Government of India to endorse e-resources and reinforce digital infrastructure all over the country. The digitization offers some of the best opportunities to provide the students with better resource and reduces disparity between institutions in terms of resource sharing. Webinar is one of the tools that help us move towards such inclusivity in education by improving accessibility as well as outreach. So, there is a high prospect of webinar in India. In this paper students' opinion on some aspects of inclusion of webinar in higher education is studied and these opinions are statistically analysed. Perception of the students under study is assembled through questionnaire. Results illustrate that though students are well versed with the use of technology, there is a lack of awareness regarding webinars. Logistic regression exhibits how the factors like age, gender, location, stream of education, access of laptop, access of mobile, access of YouTube, experience of webinar, educational infrastructure affect in the opinion of the students to incorporate webinar in higher education in recent future. We have also identified the order of the students' preference factors through a ranking process of their interest to include webinar for higher studies. The intermediate test shows that this preference probability is not uniform among the respondents. The Mann Whitney $\mathrm{U}$ statistic is used to differentiate the average perception of the students towards the preference of factors in the favour of webinar in higher education between the webinar experienced and the non-experienced groups.
\end{abstract}

Keywords Webinar $\cdot$ Stratified sampling $\cdot$ Logistic regression $\cdot$ Rank preference $\cdot$ Higher education $\cdot$ Intermediate test

Sanjib Kumar Gupta

gsanjib.stat@gmail.com

Nabanita Sengupta

nabanita.sengupta@gmail.com

1 Sarsuna College, University of Calcutta, Kolkata 700061, India 


\section{Introduction}

Communication technology has become an integral part of knowledge exchange. Over a period of time several improvements in this field have made them an indispensible part of imparting as well as sharing knowledge. One such aspect of information and communication technology or ICT has been webinar, which has a tremendous potential that waits to be explored. In the digital ecology of knowledge transference, webinar is a key player today and has a huge possibility. This paper explores students' attitude towards webinars and factors affecting it.

Webinar provides an opportunity to take the physical class to an online portal using a video conferencing system. The term 'webinar' is relatively new in the field of education. This is a combination of web and seminar. The basic idea of webinars is to conduct seminars in online mode. However, the meaning of webinars in a broader sense is not restricted to online seminars only. They now also include meetings, conferences, demonstrations, training or teaching, or events that are designed to give information either one-way or interactively. The theory of the "3I Framework" (Young et al. 2002) says students must be offered opportunities to interact with videos. Audio-visual technology has been long in use in the educational sector but with the improvement of information and communication technology, its role has become more dynamic and vast today. Among the many computermediated communication (CMC) systems, webinar is one of the latest developments. There are three formats for webinar-session delivery: (i) presenter vs. multiple participants from one site; (ii) presenter vs. multiple participants from multiple sites; and (iii) multiple participants from one site vs. multiple participants from one or multiple sites (Wang et al. 2008). In a traditional set up, the communication is generally one way with a teacher-students model of lecture where the focus is more on the lecture than on interaction or audiovisual augmentation of the content. This creates a huge gap in the content and clarity of knowledge. A shift from traditional teaching to technology-based education is required to attract the students towards higher education. There is a rising trend of digitization of education in South Asia as well as in the rest of the world which has changed in accordance with the increase in demand and gradual transformation in educational system (Risam et al. 2019; Shah 2019; Rybas et al. 2007; Cuba 2001; McKinney 2017; Kekana 2002; Siewiorek et al. 2010,2013). Webinar, a superior digital learning tool, is both a product as well as a facilitator of such a change.

Video, audio and textual communications are essential features of any webinar. Added to those, there are certain characteristics which are important in any webinar portal; some of the prominent ones being - sharing application, chat window, call option, accessibility of recording the sessions, survey window. The user has to install legitimate webinar software and then the host will send a code or link to the participants to join a seminar at the allotted time. Zoom, Google Hangouts and Meet, TeamLink, Webex, Go ToMeeting etc. are some of the widely used software which have both free and paid versions. The participant also needs a computer or smart phone with a pair of headphones and microphone. Once joined, the participant will find themselves in a virtual classroom or meeting room. The speaker or educator will deliver a lecture while other members can raise points or ask questions through the hand raising function and chat box, as provided in the software. Webinars can also be recorded and referenced at a later time. This function is useful for archiving and reviewing a session. Webinars also enable a participant to interact with other participants across the world. One of the advantages of webinar is that a large and heterogeneous audience can participate in it without having to leave their desks or homes. In this 
platform neither the speaker nor the participant needs to be present physically at the hosting venue. Therefore a greater chance of availability of resource persons is an advantage of webinar over physical seminars. Added to that, it allows real-time multimedia demonstrations and is also eco-friendly.

There are multiple reasons regarding the need to include webinars as an important educational tool. A look at the gender statistics in educational institutions in India as well as the percentage of disabled students within the academia can be taken as cases in point. NSSO's (National Sample Survey office) 75th round report, 2019 describes the varied socio-economic conditions of the students of India who enrol for higher education. Gross attendance ratio of male and female in rural sector is $20.7 \%$ and $15.6 \%$ respectively. In urban area, it is respectively $34.1 \%$ and $32.5 \%$. Net enrolment ratio in rural area is $17.7 \%$ and $13.2 \%$ respectively for male and female. The same ratio for male and female in urban sector is $29.1 \%$ and $27.6 \%$. The NSSO report shows that $36.9 \%$ male students are unable to continue their regular study because they prefer job over study for their poor economic condition and/or some future security. On the other hand, in case of female students, domestic activities (30.2\%), distant location of schools (2.7\%) and marriage (13.2\%) are the prime barriers in the path of achieving higher education. Long distance between home and institution is a deterrent to higher education not just for girls but also for physically handicapped children. While parents and guardians resist allowing their girls to travel a long distance for educational opportunities, problem increases manifold in case of differently abled students. The top 150 colleges, universities and institutes of India have less than $1 \%$ of disabled candidates enrolled as students. All these data point at the fact that Indian education system is as of now predominantly ablest and patriarchal in nature. Marginalised sectors, in terms of gender, race, economy and disability remain neglected in multiple forms. However, education through internet may reduce these disparities in India.

Another important factor is the teacher student ratio (teacher: student) which is not up to the satisfactory level in India and in the present time after inclusion of choice base credit system (CBCS) in different colleges and universities of India, infrastructural shortfall has become extremely glaring. With the number of effective teaching days reduced and teachers more engaged in making question, invigilating, checking the answer scripts, submitting the marks in portal etc., qualitative class room teaching has taken a heavy toll. With more number of choices offered, there is a huge demand for classrooms which is sadly not fulfilled in most of the institutions. In such circumstances web-based classes may be an option, to complement the classroom teaching. In many ways, it would reduce the infrastructural load on an institution. Also, there are different places in India which are prone to various kinds of natural disasters. A number of teaching-learning days are lost each year due to these disasters as students and teachers find unable to reach the educational institute. During such times online mode of teaching can provide a way out. Any student suffering from any health issues that restrict movement may also continue his/her study through online. Webinar is very much useful at the time of pandemic situation too, provided that the internet connection remains smooth. Thus, in a country with disparate infrastructural facilities, access to resources, diversity of academic ecology and geographic vulnerabilities like India, webinars can play the role of a great leveller. In fact, webinars would help in the democratisation of educational resources in India. One of the reasons is that it would help in a seamless transfer of resources from one institution or scholar to another or many, irrespective of their places of location.

These were the reasons behind organising the webinar at Sarsuna College, funded by Indian Council of Social Science Research (ICSSR) and in collaboration with five other universities of India and Bangladesh. There was a wide range of participation including 
eminent educators, professors, scholars and students during the event. The idea behind organising such an event on the topic of "Higher Academics in South Asia: Changing Perspectives" on 25th and 26th February 2019 was to organise an exchange of views regarding the changing ecology of the academic sector. The event was well attended by students and faculty members of collaborating institutions, namely, Centre for Comparative Literature, Visva-bharati; Centre for Applied Linguistics and Translation Studies, Hyderabad University; School of Education Studies, Ambedkar University and Department of Bengali, Vidyasagar University. Feedbacks of the participants regarding their experience and understanding the webinar were collected. The questions were chiefly related to the various aspects of webinar and factors that influence it. Thereafter, we considered doing a survey throughout India to get feedback regarding students' opinion on webinar and its future in higher education. This paper contains the data analysis of that survey.

A short literature review of the existing study on webinar is important here. The term 'webinar' was first introduced by Eric R. Korb in 1998 (Korb 2000). As of now, there has not been much study in this field. Gegenfurtner et al. (2019) reviewed different issues related to webinar. The Merriam-Webster Online Dictionary, 2010 defined a webinar as a "live online educational presentation in which participating viewers can submit questions and comments". According to Pan et al. (2005) webinars provide just-in-time learning. Wang et al. (2008) discussed how webinars can strengthen the social presence for all participants. Dupuis et al. (2013) studied the effect of problem solving videos applied in a molecular biology course for upper level undergraduate students and they found that the complimentary online video have a positive and significant effect on examination scores. Hove et al. (2008) reported that those students who in addition to the traditional chalk and talk mode of education had a limitless access to recorded videos on the subject of 'Introduction to psychology' achieved better grades in that subject as compared to those who did not have any such access. Zhang et al. (2006) claimed that better learning performance can be achieved using interactive videos. Nagy et al. (2015) showed the positive impact of webinar on learning performance. Verma et al. (2010) talked about the shift in the learning habits and technologies and the impact that webinar can make as a learning technology taking a case study from campus connect team of Infosys technology Ltd. Some papers explore how webinar tools can encourage interaction in web-based educational environment. Research on educators' experience in use of webinars has been carried out (Ahrens et al. 2015). Cheng et al. (2005) shows that the students of Cyber university of Taiban are satisfied with the education through webinar. Nelson (2010) observed that there is no significant difference in learning outcomes of synchronous webinar versus classroom instruction among 224 nursing students. Lieser et al. (2018) presented a three-stage process of developing a webinar integration tool to enhance the interaction of teaching and learning in blended environments. Kohorst et al. (2007) depicted that a webinar system is very much effective. Alnabelsi et al. (2015); Power et al. (2014); Tseng et al. (2019) discussed different merits of a webinar.

In the literature review we have seen that statistical analysis of the opinion of students towards different features of webinar and their willingness to accept it in higher education is very limited. To formulate future policies in the educational sector it shall be of paramount importance to access the opinion of students and decide accordingly. The goal of this study is to identify the multiple factors that significantly influence the opinion. Different factors such as age, location, gender, accessibility of smart phone, accessibility of computers, previous experiences of attending webinars, education through YouTube, stream of study, institutional infrastructures are considered as independent variable and the perceptions of students on webinar are taken as dependent variable in this context. To the 
best of our knowledge none of the existing literature deals with these relationships. It may help the government and policy makers of India to identify and understand the demand and perception of students regarding various aspects of education to promote online education at least partially in higher education. The prime objective of this paper is to statistically study the association between the factors considered and the students' perception of the same. One may test the hypotheses using chi-square test. But instead of that, a binary logistic regression is used in this paper to test the significant effect of the above mentioned independent variables under study on the opinion of students regarding different factors of webinar. Another objective of this paper is also to rank the factors responsible for including webinars in higher studies, according to their importance as rated by the students. We have obtained the preference rank of different factors that may influence the need to assimilate webinar within the scope of higher education. Students under study were asked to assign rank to the factors that may influence a webinar. We have prepared a frequency table from which we have ranked the factors according to the preference of the respondent. Intermediate test statistic (Abayomi et al. 2013) is the test that we have used for the analysis of preference data. We have also conducted a test to judge the preference score of those students who are already familiar with webinar and those who did not are same or not.

This paper is organised in the sequential order. After this introductory discussion of Sect. 1, Sect. 2 discusses the data collection method and the methodology applied for the study. Results are presented in Sect. 3. Section 4 deals with the discussion of the work and the conclusion of the paper.

\section{Data Collection and Methods}

After the webinar organised by Sarsuna College a questionnaire was distributed among both the participating and non-participating students of the host college as well as other higher educational institutions of India. The basic concept of webinar was explained at the beginning of the questionnaire for the understanding of those who were still uninitiated into this concept. A Google form was created to collect response, so that students could respond to the form even from their mobile phones or tablets. The forms were sent through email and social media and each recipient as well as respondent was requested to share the form widely among their peers. This is actually a concept of snowball sampling (Goodman 1961). It helped in fast inflow of data from various respondents. However, some questionnaires were filled offline also, from the remote areas where proper internet connection was not available or where the students did not have access to laptops or smart mobile phones. So, we had applied random sampling and snowball sampling to collect data in a short time span from 25th February, 2019 to 31st December, 2019. We received a total of 14,317 responses from under graduate and post graduate students across India through online and off-line modes. The responses were gathered and tabulated on an excel sheet. The responses have been categorised into three parts. In the part 1 the information related to name, age, gender, area, email id, name of the institution, stream of study, class/year, mode of study, access to mobile phone, access to computer are marked. The second part consists of closed or yes/no based responses corresponding to different issues of webinar and YouTube. Ranked responses are retained in the third part of the excel sheet. In the reduced spreadsheet file the three parts of the data with two respondents are represented as depicted in Table 1, Table 2 and Table 3. The original name of the respondents, institutions and mail identifications are not disclosed here to maintain confidentiality. 


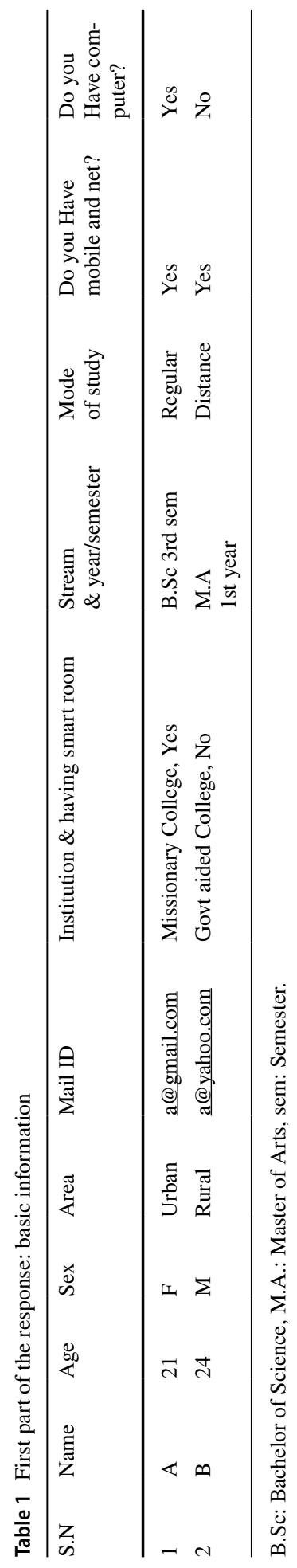




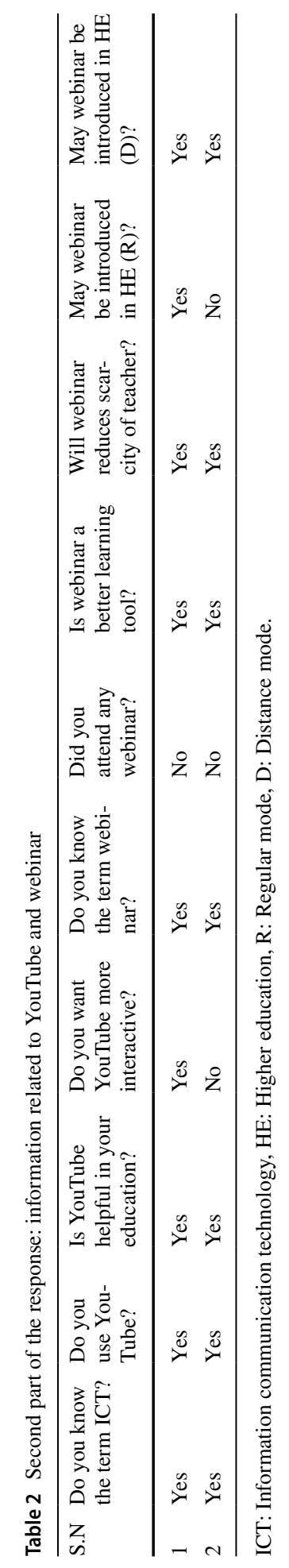




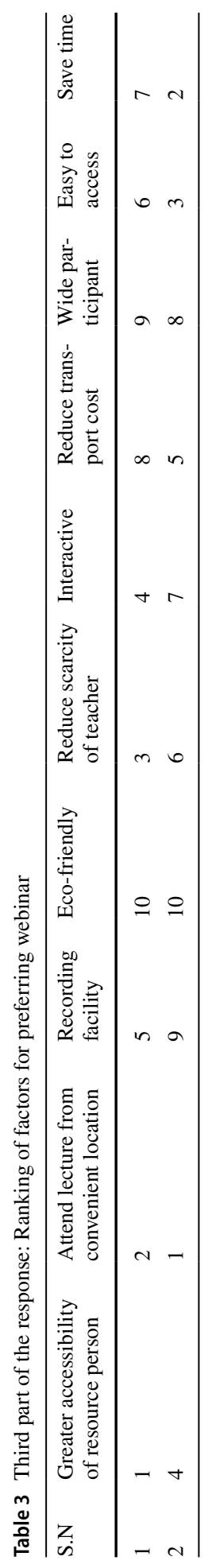


We have also prepared two different strata to distinguish respondents on the basis of their experience of attending webinars - the strata of those with the experience of attending webinars is smaller than those who have not attended any. Since the samples are not entirely random, to bring randomness in it we have again drawn samples using population proportion stratified sampling from each stratum. We have ultimately worked with 6350 samples. Then the data have been statistically analysed. Here the key variables under study are the students' opinion regarding the following matters-(i) webinar as a better learning tool, (ii) whether webinar can reduce the scarcity of teacher, (iii) inclusion of webinar in regular higher education and (iv) incorporating webinar in distance education. These opinions are considered as dependent variables. Independent variables that have been considered are age, gender, location, stream of study of students, accessibility of computer, accessibility of smart mobile phone, infrastructure of the institute, use of YouTube for study purpose through internet, whether attend or not a webinar are the independent variables. The null hypotheses $\left(H_{0}\right)$ of the tests, independent of the students' opinion with respect to different factors under study, can be represented in Table 4. Here, the alternative hypothesis $\left(H_{1}\right)$ is that the factors are associated with the students' opinion.

We have performed regression of the four key dependent variables (students' opinions) separately with the relevant explanatory variables. Here, it is to be noted that the response variables are binary in nature and hence simple regression is not useful. This is why we have performed a binary logistic regression. The binary logistic regression is the suitable regression analysis to perform when the dependent variable is binary (Agresti 1990). Except age of the respondent, all the independent factors are also binary. The value 0 and 1 were assigned with the dependent and independent variables in the following way.

$\mathrm{A}_{\mathrm{i}}=1(0)$ if the ith student thinks (does not think) that webinar is a better educational tool.

$\mathrm{B}_{\mathrm{i}}=1(0)$ if the ith student think (does not think) that webinar can reduce the scarcity of teacher.

$\mathrm{C}_{\mathrm{i}}=1(0)$ if the ith student think (does not think) that webinar can be included in regular higher studies.

$P_{i}=1(0)$ if the ith student think (does not think) that webinar can be included in distance education.

$\mathrm{S}_{\mathrm{i}}=1(0)$ if the ith student is male (female).

$\mathrm{L}_{\mathrm{i}}=1(0)$ if the ith student from urban (rural) area.

$\mathrm{T}_{\mathrm{i}}=1(0)$ if the ith student from science (humanities) stream.

$\mathrm{M}_{\mathrm{i}}=1(0)$ if the ith student accesses (does not access) smart mobile with internet.

$\mathrm{R}_{\mathrm{i}}=1(0)$ if the ith student accesses (does not access) computer.

$\mathrm{D}_{\mathrm{i}}=1(0)$ if the ith student accesses (does not access) YouTube for his study purpose.

$I_{i}=1(0)$ if the infrastructure of the educational institution of the ith student is good (not good).

$\mathrm{W}_{\mathrm{i}}=1(0)$ if the ith student attended (did not attend) any webinar.

Here, $i=1,2,3, \ldots, n$ and $n=$ number of individuals under study.

We used SPSS software to carry out the logistic regression.

In general, If $\mathrm{y}$ is a binary response, $x_{1}, x_{2}, \ldots, x_{k}$ are the explanatory variables and $\pi=\mathrm{P}(\mathrm{y}=1)$, then the $\log$ model is:

$$
\ln \left(\frac{\pi}{1-\pi}\right)=b_{0}+b_{1} x_{1}+b_{2} x_{2}+\ldots+b_{k} x_{k}
$$




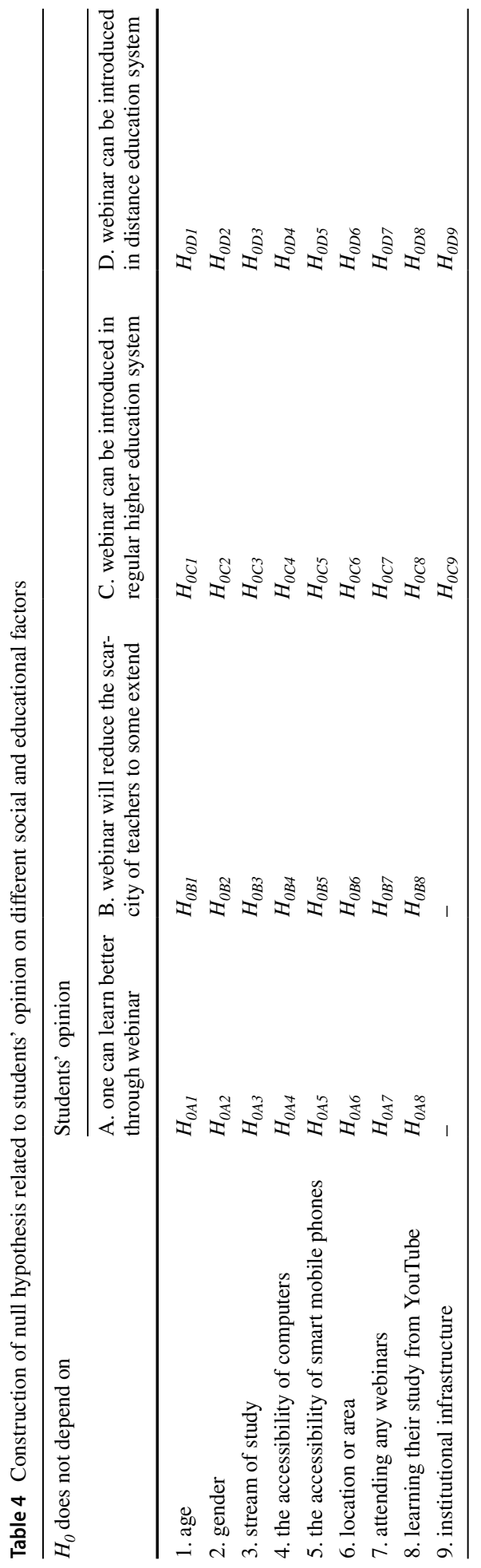


Here, $b_{0}, b_{1}, b_{2}, \ldots, b_{k}$ are the coefficients of explanatory variables. These coefficients are determined by the probabilistic framework called maximum likelihood estimation.

In this paper, we have applied four logistic regressions corresponding to four models (Model 1, Model 2, Model 3 and Model 4). In Model 1, we have studied the relation between the opinion of students whether webinar is a better educational tool against age, gender, stream, location, accession of mobile, accession of computer, use of YouTube for education, whether attended webinar or not. In Model 2 all the independent factors are same but the dependent factor is the opinion of students whether webinar can reduce scarcity of teachers. In Model 3 and Model 4 the dependent variables are the opinion of inclusion of webinar in regular higher education and distance higher education respectively and independent variables are same with extra addition of infrastructure of educational institute. We have calculated p-values to test the influence of the factors. If the p-value for the test corresponding to the coefficients of the explanatory variables is less than certain standard fixed value of the level of significance, say $\alpha \in(0,1)$, then the explanatory variable has a significant effect at the level $\alpha$. Generally, up to $\alpha=0.05$ we consider higher significant effect. However, if $0.05<\alpha<0.10$ then we can also say the corresponding factor has a small significant effect.

Then we have calculated the preference index of the factors that may play role to influence students to adopt webinar in higher studies. To assign the preference index we have assigned number 1 to the least favourable and 10 to that which is the most favourable and similarly the intermediate values $2,3,4, \ldots, 9$ were assigned according to the increasing sequence of the preference. The intermediate statistic is applied to know whether all the alternatives on why the students choose webinar in their education system have the same probability with respect to their preferability. This test illustrates whether at least one alternative is significantly preferable to the others. It is a test between the multinomial and Freidman test statistics. Finally, the Mann-Whitney U statistic is implemented to judge whether the average preference score of webinar experienced group is alike of non experienced group.

\section{Results}

Sarsuna College, under the University of Calcutta, had organised a two-day webinar on 25th and 26th February, 2019 at the College premises. More than 250 individuals across the world including teachers, students, research scholars, eminent academicians attended it. Prof. Dipesh Chakraborty from University of Chicago and Prof Rahul Gairola from Murdoch University were among the eminent speakers of the webinar along with other important professors and scholars from India and Bangladesh. The second author of this paper was one of the convenors of the webinar and the first author was a member of the organising committee. During the webinar feedback was collected from the participants through a questionnaire regarding general concepts and features of a webinar. We saw that most of the participants had not experienced a webinar before it was organised by Sarsuna College. Also, a large number of participants responded that they have heard the term webinar for the first time here. Later the questionnaire was sent among different teachers, students, scholars and to all those who were related to higher academics, irrespective of attendance of a webinar. As we mentioned earlier, we have ultimately analysed the data on the basis of 6350 under graduate and post graduate students in India only. Detail sampling scheme has been discussed in the previous section. 
The data was arranged in an excel sheet as per requirement. We have seen that among the selected respondent in the sample $67 \%$ is male and $33 \%$ is female. The age of the respondent is between 18 to 27 years. The students from science and humanity streams are respectively $32 \%$ and $68 \%$. There are $31 \%$ respondents from rural area and remaining were either from urban or semi urban area. 71\% students have heard about ICT. 55\% respondents access YouTube for educational purpose. $46 \%$ respondents feel that it will be beneficial for them if YouTube becomes more interactive. This proves that there is a demand for online interactive lectures among the students of India. However, only 33\% respondents have heard the term webinar earlier. So, there is a lack of awareness regarding utility of webinar. Though there is a demand for interactive online classes, owing to absolutely no information regarding webinar there has been no need felt for it. Only $15 \%$ of the respondents have attended any webinar. $87 \%$ among non-attendees want to attend webinar at least once. So, by testing different hypotheses to identify the dependence between the willingness of students regarding inclusion of webinar in higher education and different factors like age, gender, experience of attending a webinar etc. as we have discussed on previous section several logistic regressions have been performed. The results are given below.

Table 5 represents the result of the logistic regression corresponding to Model 1 where the opinion of whether webinar is a better learning tool or not is the dependent variable and age, gender, stream, access to computer, area or location of the student, experience of attending webinar and access to YouTube for the study purpose are the independent variables.

We have seen that computer access, previous experience of attending webinar and access to YouTube are the three factors that strongly influence the decision with higher significance regarding whether webinar is a good educational tool or not. The decision is independent of other factors. Those students who have an access to computers have a better understanding of the ways in which webinars are better tools for education. Similarly, those who have attended any webinar they on an average respond that webinar is a better learning tool. But those are not experienced with webinar they did not understand the proper utility of it as an educational tool. Also, those who collect study material from YouTube they are also agreed that webinar is a better educational tool.

Table 5 Logistic regression of the perception of webinar as a better learning tool on the independent variables

\begin{tabular}{lllll}
\hline Factors & $\begin{array}{l}\text { Coefficient } \\
(b)\end{array}$ & Standard error & Wald statistic & Significance \\
\hline Constant & -6.306 & 4.744 & 1.767 & 0.184 \\
Age & 0.119 & 0.220 & 0.293 & 0.588 \\
Gender & -1.012 & 0.652 & 2.409 & 0.121 \\
Stream & 0.155 & 0.524 & 0.087 & 0.768 \\
Computer & 1.731 & 0.584 & 8.785 & $0.003^{* * *}$ \\
Mobile & 0.090 & 1.181 & 0.006 & 0.938 \\
Area & 0.432 & 0.583 & 0.549 & 0.459 \\
Attend Webinar & 3.055 & 0.657 & 21.622 & $0.000^{* * *}$ \\
Use of YouTube & 3.051 & 0.858 & 12.645 & $0.000^{* * * *}$ \\
\hline
\end{tabular}

‘***’ Very high significant $(<0.01)$. 
In Table 6 we have presented the result related to the logistic regression corresponding to Model 2. Here the dependent variable is the opinion of whether the webinar can reduce the scarcity of teachers to some extent and the independent variables are same that we have considered in Model 1.

From the Table 6 we can say that stream of education, computer access, locality of the students, webinars attended are strongly depend on the decision whether webinar can reduce the scarcity of teacher or not. This table also reflects the digital divide as prevails in India between the digitally abled and digitally disabled, depending on one's geographical location, economic status as well as digital awareness. This was reflected in their responses as well - those with access to computers, thought that they could listen to lecture from their own convenient place and can acquire knowledge on the subject which has less teacher at the institution. On the other hand, those who have no access to computers did not have much idea regarding the utility of the webinars as they were mostly not aware of it. Students of science stream are more often hampered by scarcity of teacher than the humanity streams. The condition of internet in rural area is not up to the mark. So, the students are scared of not being able to access the lectures from their area. Those who attended the webinar have experienced the quality of lecture and hence they thought it may supplement the lack of teachers in their respective disciplines. Access of YouTube also reflects a small effect on the opinion of the respondents. The students who use YouTube for academic purpose they also feel that it may reduce the scarcity of teacher.

We have analysed Model 3 and the results are depicted in Table 7. Here, the opinion of students regarding the necessity of including webinars in regular higher education is taken as the dependent variable and age, gender, stream of education, computer access, mobile access, area or locality of the student, experience of attending webinars, infrastructure of the institution and the access to YouTube are taken as independent variables.

The Table 7 highlights the fact that area or locality, experience of attending webinars, infrastructures of institution have significant effect on the decision whether webinar can adopt or not in higher education (regular mode). The technological facilities of the institution of urban and semi urban area are greater than the rural area. This is why more number of students from urban and semi urban area with improved educational infrastructure preferred webinar for their education purpose than students from rural area. YouTube access has moderate significant effect on the decision. The students who have attended webinars

Table 6 Logistics regression of the opinion of reduction scarcity of teacher on the independent variables

\begin{tabular}{lllll}
\hline Factors & $\begin{array}{l}\text { Coefficient } \\
(b)\end{array}$ & Standard error & Wald statistic & Significance \\
\hline Constant & 0.577 & 3.713 & 0.024 & 0.876 \\
Age & 0.154 & 0.181 & 0.724 & 0.395 \\
Gender & -0.208 & 0.509 & 0.167 & 0.683 \\
Stream & 0.997 & 0.432 & 5.326 & $0.021^{* *}$ \\
Computer & 1.068 & 0.520 & 4.218 & $0.040^{* *}$ \\
Mobile & 0.842 & 0.853 & 0.974 & 0.324 \\
Area & 1.338 & 0.493 & 7.366 & $0.007 * * *$ \\
Attend Webinar & 1.564 & 0.543 & 8.296 & $0.004 * *$ \\
Use of YouTube & 0.955 & 0.511 & 3.493 & $0.062 *$ \\
\hline
\end{tabular}

‘***’ Very high significant $(<0.01)$, ‘**’ significant $(0.01-0.05),{ }^{*}$ ’ small significant $(0.051-0.1)$. 
Table 7 Logistic regression of opinions regarding inclusion of webinar in regular higher academic for educational purpose on the independent variables:

\begin{tabular}{lllll}
\hline Factors & $\begin{array}{l}\text { Coefficient } \\
(b)\end{array}$ & Standard error & Wald statistic & Significance \\
\hline Constant & -2.866 & 3.597 & 0.635 & 0.426 \\
Age & 0.006 & 0.174 & 0.001 & 0.975 \\
Gender & -0.291 & 0.495 & 0.345 & 0.557 \\
Stream & 0.254 & 0.436 & 0.340 & 0.560 \\
Computer & 0.629 & 0.536 & 1.377 & 0.241 \\
Mobile & 0.742 & 0.941 & 0.622 & 0.430 \\
Area & 0.992 & 0.368 & 7.267 & $0.007 * * *$ \\
Attend Webinar & 1.729 & 0.594 & 8.473 & $0.004 * * *$ \\
Infrastructure of Institution & 2.049 & 0.474 & 18.687 & $0.000^{* * *}$ \\
Use of YouTube & 1.205 & 0.475 & 6.436 & $0.011 * *$ \\
\hline
\end{tabular}

‘***’ Very high significant, ‘**’ significant.

are more in favour of introducing webinars in higher education than those who did not experience.

Table 8 analyses the logistic regression corresponding to Model 4. Here we take the opinion of students regarding inclusion of webinar in distance education as dependent variable and age, gender, stream, computer access, mobile access, area or locality of the student, experience of attending webinars, infrastructure of the institution and YouTube access as independent variable.

Age and YouTube are the significant factors to decide upon inclusion of webinar in distance education. On the other hand, area or locality, experience of attending webinars, institutional infrastructure have small significant effect on the decision.

We asked students to assign rank to factors they consider most influential in determining the inclusion of webinar in higher studies. The factors were to be marked on a scale of 1 to

Table 8 Logistic regression of opinion regarding inclusion of webinar on distance education on the independent variables

\begin{tabular}{lclll}
\hline Factors & $\begin{array}{l}\text { Coefficient } \\
(b)\end{array}$ & Standard error & Wald statistic & Significance \\
\hline Constant & 0.547 & 3.904 & 0.020 & 0.888 \\
Age & 0.406 & 0.184 & 4.869 & $0.027^{* *}$ \\
Gender & -0.431 & 0.510 & 0.714 & 0.398 \\
Stream & 0.446 & 0.446 & 1.000 & 0.317 \\
Computer & 0.663 & 0.561 & 1.397 & 0.237 \\
Mobile & 1.238 & 0.870 & 2.025 & 0.155 \\
Area & 0.907 & 0.505 & 3.226 & $0.072^{*}$ \\
Attend Webinar & 1.475 & 0.784 & 3.540 & $0.060^{*}$ \\
Infrastructure of Institution & 0.974 & 0.536 & 3.302 & $0.069^{*}$ \\
Use of YouTube & 1.349 & 0.496 & 7.400 & $0.007 * *$ \\
\hline
\end{tabular}

‘***’ Very high significant, ‘**’ significant, ‘*’low significant. 
10 with the most preferable factor to be assigned rank 1 and least preferable to be ranked 10. On the basis of the given rank by the respondent we first calculated the percentage of frequencies of ranks corresponding to each factor separately. Then the more preferable factor was assigned score 10 and least preferable factor assigned score 1 according to the decrease in preference opinions. Then we calculated the total preference score. Preference scores and preference ranks are given in Table 9. On the basis of the preference score we can conclude that greater accessibility of the resource person is the most preferable factor and eco-friendly nature of webinar is the least preferable factor. That webinars can be a tool to reduce the scarcity of teacher is the second preferable factor and its archival nature, that it can be archived for later access is the third in list of preferences. The fourth preferable factor is attending lecture from their convenient location. Interactive nature of the webinar is the fifth preference factor among the students. Similarly, the sixth, seventh, eight and ninth preference factors are respectively ease of access, reduction of transport cost, wide reaching participants and saving time.

If we use the intermediate test then the p-value of the chi-square test statistic is 0.001. This result suggests that the preference chance of all the factors to choose webinar is not uniformly distributed. Thereafter, we examined whether the preference of the students who have attended webinars and those who did not, match. p-value corresponding to the Mann Whitney $U$ statistic is 0.037 . So, the preference of the two groups is not same. We have seen that the perception score among the webinar attendee is higher than that of non-attendee.

\section{Discussion and Conclusions}

The analysis of this paper shows that most students are interested in attending some interactive online lectures. YouTube is one of the available platforms from where student can study different topics. But the interaction between the teacher or presenter and the students is restricted only in the form of message as comment or live chart only. Face to face interaction is required to clear doubts and get proper knowledge. In this direction webinar is a good educational tool. This enables students to interact face to face through a computer or mobile in real time and therefore is much more effective in imparting knowledge. Since, there is a huge lack of awareness regarding webinars among students; most of the students are not able to benefit from its use. In India, very few webinars have been conducted till the time of writing this paper. In West Bengal, a state of India, probably Sarsuna College is the pioneer in conducting webinar. Thus, it is required to organise many more webinars to spread the utility of webinar among the students. The survey shows that most of the students in an urban locality coming from an average economic background possess computer and/or smart mobile phone and thereby it will be easier to participate in a webinar. However, many of those students, especially those who did not attend any webinar hesitated regarding the possibility of attending a webinar via their devices.

The result suggests that opinion of students regarding usefulness and viability of a webinar is independent of the gender of the respondent. Thus, the reasons for inclusion of webinar in higher academics are similar among both male and female students. This survey also showed that opinion is independent of students' possession of a smart phone. The reason behind this can be that most of the students under this survey carry mobile phones and those very few who still do not, know the merits and demerits of mobiles from their friends. This is why access of mobile or not has no significant effect on the decision of students regarding the different matters of webinar under study. But we have to keep in mind 


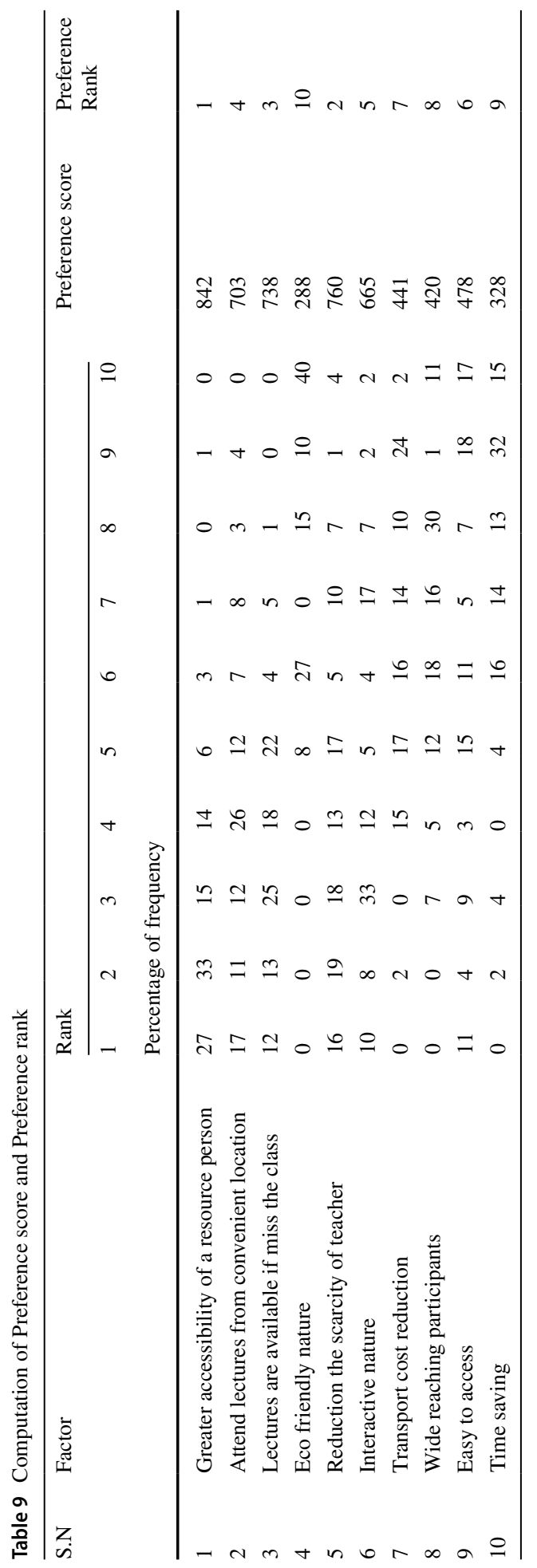


that this survey does not include all kinds of students within the spectrum. Age is independent of the other factors under study except regarding its inclusion in distance mode of education. Among the students participating in the survey, in general higher the age, higher is the class in which they are enrolled. The students enrolled in higher classes may understand that the number of seats for higher education is limited and they have to join a job to secure future. So, distance education is a good option for them and if they can access webinar for their study, they can attend lecture from their convenient location. Students with interrupted academic career also want to finish their higher education quickly and they too consider that webinars can supplement their lack of physical classes. Stream of a student is the only influencing the opinion regarding webinar reducing the scarcity of teacher. The teacher-student ratio is not very encouraging in most of the higher educational institute. Setting up of a number of new institutions without filling up vacancies for teachers in the existing ones have led to a major fall in teacher-student ratio. Students enrolled in practical based subjects are the greater sufferers in this case. Thus, the students of science stream are more eager to think webinar as a partial and temporary replacement of a teacher if the teacher of some specific subject or topic is not available or as an addition to their regular class. Opinion of students regarding webinar being a better educational tool, irrespective of its inclusion in higher academics, whether in distance or regular mode, is independent of the stream of the student. Accession of computer is an important indicator in the favour of webinar in higher studies. It influences the opinions of whether webinar is a better educational tool and whether webinar can reduce scarcity of teacher. Since the students having computer are more used to different online educational tools than those who do not have, they think that webinar is a better educational tool and may reduce the scarcity of teacher. However, to favour the introduction of webinar in education, whether in regular or distance mode, does not depend on the individual's access to computer. From the outcome of the analysis we can say, area or locality of the student affects the opinion on different aspects of webinar in higher academics under study. Except to recognise webinar as a better educational tool all other decisive variables depend on the locality of a student. The internet connection and other infrastructure are not satisfactory at many educational institutes of rural India. On the other hand, semi urban area and urban area are well equipped with internet and other infrastructural facility. The students of rural area are not sure whether inclusion of webinar will be viable for them or not and whether it would reduce the scarcity of teacher for them.

The opinions regarding inclusion of webinars in higher academics that have been considered here depend highly on whether a student attends a webinar or not. It is expected that a student who has attended a webinar will be better aware of the merits and demerits of webinar. Such students are more positive towards various aspects of webinar than a student who has never attended any such. Also, those with an experience of using YouTube for academics are more favourable to using webinars in academics than those who do not use YouTube. YouTube users are used to gaining knowledge and information from online videos. So, they understand the utility of online lectures. Survey also suggests that they are eager to have a real time interactive online platform and webinar might fulfil their requirement.

Institutional infrastructure is another key factor for students. A student is in favour of inclusion of webinar in his or her institution, if the infrastructure of the institution is good. But if the infrastructure is not well enough then the students are not so much in favour of incorporating it within the regular structure of higher education.

Preference score and corresponding preference rank of the factors are good indications of the demand of the students to adopt webinar in higher education. Availability of the 
resource person is the prime factor in favour of webinars. The students may prefer webinar because the resource person can be available easily. Since the resource persons need not go to the lecture venue, the probability of accessibility is high and students think they will be benefited to attend quality lectures from eminent academicians all over the world. Students also think that if webinar reduces the scarcity of teacher then they will attend it and considered this factor as second in the order of preference. In case of traditional chalk and talk or power point based classes, mostly the lectures are not recorded and thereby if anybody misses it then he or she will not able to listen it. But different webinar softwares have inbuilt process to record the audio and video of lecturers and thereby student will be able to listen to them at his/her convenient time. So, this feature of webinar is ranked in third place. Attending lecture from their convenient location is the fourth priority index among the students. It may help the students to attend the class even on holidays and also without travelling from home. Interactive nature of the webinar through video is another attractive feature of the webinar and students have ranked it at number five. Unlike in other modes like YouTube and other video platforms, webinars provide with a real time interaction between speakers and audience. With a strong internet connection, a proper mobile phone or computer, a person can easily attend the webinars and this is what makes webinars so accessible for students. This factor has preference rank six. Since, one can attend the webinar from their own location there is no transport cost to attend it and students considered this reduction of transport cost as seventh in preference list. The students are interest on making friends and interact with them also. Thus, the wide range of audiences is the eighth preference factor. Time saving and eco-friendly nature of webinars are two least preferable indicators for the student.

Thus overall the students are in favour of inclusion of webinar in higher studies. It is required that more number of webinars are organised so that students can familiarise themselves with the merits and demerits of the webinar. They can then decide for themselves whether inclusion of webinars in higher education is advantageous or not and also think of ways to reduce its demerits. On the basis of the students' opinions regarding webinars the Government of India may also take some necessary steps to improve the educational infrastructure by making digital platforms more accessible for students from all sections of the society.

The world at present is suffering from the pandemic Corona (Covid-19) virus and most of the educational institutes are forced to close physical classes and move online. Webbased classes are very useful to continue the students' education process in the current scenario of social distancing. The data for the present paper have been collected before the pandemic Covid-19 and represents a world where webinars had not yet become normal. There has been a drastic change in the knowledge sharing ecology across world within a span of a few months. But whether this change will be sustainable or not needs to be seen in a post Covid-19 world. Also, in order to study the growth and development of webinars and their acceptability as an educational tool by students of higher academics, it is important to assess their function and presence in the pre-Covid, current and post Covid situations.

There are some challenges in adoption of webinars in higher education such as unavailability of sufficiently trained teachers, lack of well-equipped technically sound class rooms, inadequate number of computers, poor internet accessibility in the remote areas, paid software not affordable for students, discontinued flow of electricity, timings of online classes, maintenance of mobile, computer etc. Another problem is the awareness of webinars in the society. As Das (2012) mentioned while discussing challenges of ICT that it should not lead to the formation of greater divide, that it should not increase the existing schisms 
in the dominant social structure of Indian society, namely that between urban and rural India, rich and poor, cosmopolitan, mainland and remote, border areas, male and female and caste-based divisions. While ICT enabled webinars can be a boon in bringing about inclusivity in the society, it should also be used with caution. Kundu et al. (2018) talked about different obstacles to utilize ICT in Indian education system. However, a detailed planning can prevent a wide range of frustrating problems regarding webinar technology. Consultation with instructional design and/or technology support staff can be very helpful with this process (Senecal et al. 2010). So, the government has to carefully consider these issues while implementing webinar as an educational tool in higher academics in India.

One drawback of this paper is that it did not cover all the universities of India. Some key universities could not be considered in the sample. So, in future it is required to consider all those universities and more cross sections of the society. This will be much time-consuming. However, in future we want to make state wise comparison of students' opinion regarding different aspects of webinar. Efficiency of webinar in various states would be determined using data envelopment analysis (DEA) (Charnes et al. 1978) and the determinants of the efficiency may be identified through Tobit regression or ordinary least square method (McDonald 2009). Different statistical tools like factor analysis, principal component analysis, multinomial logistic regression, composite index may be applied to critically analyse the opinion of the students.

\section{References}

Abayomi, A. A., \& Muyiwa, J. S. (2013). Analysis of preference data using intermediate test statistic. West African Journal of Industrial and Academic Research, 7(1), 101-104.

Agresti, A. (1990). Categorical data analysis. New York: John Wiley and Sons.

Ahrens, A., Zaščerinska, J., Melnikova, J., Ramar, H., Clipa, O., \& Andreeva, N. (2015). Use of webinars in higher education: A comparative study of educators' experience. 3rd Annual International ScientificPractical Application Conference Trends in Science and Higher Education Studies under Conditions of Globalization. Panevėžys College, Panevėžys, Lithuania., 56, 22-29.

Alnabelsi, T., Al-Hussaini, A., \& Owens, D. (2015). Comparison of traditional face-to-face teaching with synchronous e-learning in otolaryngology emergencies teaching to medical undergraduates: a randomised controlled trial. European Archives of Oto-Rhino-Laryngology, 272, 759-763.

Charnes, A., Cooper, W. W., \& Rhodes, E. (1978). Measuring the efficiency of decision making units. European Journal of Operations Research, 2(6), 429-444.

Cheng, N. S., Ko, H. C., \& Kinshuk, \& Lin, T, . (2005). A model for synchronous learning using the internet. Innovations in Education and Teaching International., 42(2), 181-194.

Cuba, L. (2001). Oversold and underused: Computers in the classroom. Cambridge, MA: Harvard University Press.

Das, R. (2012). Integrating ICT in teaching learning framework in India: Initiatives and challenges. Bhatter College Journal of Multidisciplinary Studies., 85, 21-27.

Dupuis, J., Coutu, J., \& Laneuville, O. (2013). Application of linear mixed-effect models for the analysis of exam scores: Online video associated with higher scores for undergraduate students with lower grades. Computer and education, 66, 64-73.

Gegenfurtner, A., \& Ebner, C. (2019). Webinars in higher education and professional training: A meta-analysis and systematic review of randomized controlled trials. Educational Research Review, 28, 1-19.

Goodman, L. A. (1961). Snowball sampling. Annals of Mathematical Statistics, 32(1), 148-170.

Hove, M., \& Corcoran, K. (2008). If you post it, will they come? Lecture availability in introductory psychology. Teaching of Psychology, 35(2), 91-95.

Kekana, N. (2002). Information, communication and transformation: A South African perspective. Communicatio, 28(2), 54-61.

Kohorst, K., \& Cox, J. R. (2007). Virtual office hours using a tablet PC: E-lluminating Biochemistry in an online environment. Biochemistry and Molecular Biology Education, 35(3), 193-197.

Korb, E. R. (2000). U.S. registered trademark serial no. 75478683. Washington, DC: U.S. Patent and Trademark Office. 
Kundu, A., \& Nath, D. K. (2018). Barriers to utilizing ICT in education in India with a special focus on rural areas. International Journal of Scientific Research and Reviews, 7(2), 341-359.

Lieser, P., Taff, S. D., \& Hang, A. M. (2018). The webinar integration tool: A framework for promoting active learning in blended environments. Journal of Interactive Media in Education, 1, 1-8.

McDonald, J. (2009). Using least squares and Tobit in second stage DEA efficiency analyses. European Journal of Operational Research, 197(2), 792-798.

McKinney, W. P. (2017). Assessing the evidence for the educational efficacy of webinars and related internet-based instruction. Pedagogy in Health Promotion: The Scholarship of Teaching and Learning, 3, 475-515.

Ministry of Human Resource Development (2019). All India survey on Higher Education 2018-19. Retrieved from-https://mhrd.gov.in/sites/upload_files/mhrd/files/statistics-new/AISHE\%20Final\%20 Report\%202018-19.pdf.

Nagy, J. T., \& Bernschütz, M. (2015). The impact of webinar-webcast system on learning performance. Education and Information Technologies, 21(6), 1837-1845.

Nelson, L.S. (2010). Learning outcomes of webinar versus classroom instruction among baccalaureate nursing students: A randomized controlled trial. ProQuest Dissertations and Theses, College of Nursing, Denton, Texas. Retrieved from http://hdl.handle.net/11274/287.

Pan, C. C., \& Sullivan, M. (2005). Promoting synchronous interaction in an elearning environment. T. H. E. Journal, 33(2), 27-30.

Power, M., \& St-Jacques, A. (2014). The graduate virtual classroom webinar: A collaborative and constructivist online teaching strategy. Journal of Online Learning and Teaching/MERLOT, 10(4), 681-696.

Risam, R., \& Gairola, R. (2019). South Asian digital humanities then and now. South Asian Review, 40(3), $141-154$.

Rybas, N., \& Gajjala, R. (2007). Developing cyberethnographic research methods for understanding digitally mediated identities. Qualitative. Social Research, 8(3), 35. https://doi.org/10.17169/fqs-8.3.282.

Senecal, J., \& Gazda, R. (2010). Harmonizing the virtual choir: interactive synchronous webinars for online education. Journal of interactive instruction development, 21(3), 13-16.

Siewiorek, A., \& Gegenfurtner, A. (2010). Leading to win: The influence of leadership style on team performance during a computer game training. In K. Gomez, L. Lyons, \& J. Radinsky (Eds). Learning in the disciplines, Chicago, IL. 1; 524-531.

Siewiorek, A., Gegenfurtner, A., Lainema, T., Saarinen, E., \& Lehtinen, E. (2013). The effects of computersimulation game training on participants' opinions on leadership styles. British Journal of Educational Technology, 44, 1012-1035.

Shah, N. (2019). Digital humanities on the ground: Post-access politics and the second wave of digital humanities. South Asian Review., 40(3), 155-173.

Tseng, J.-J., Cheng, Y.-S., \& Yeh, H.-N. (2019). How pre-service English teachers enact TPACK in the context of web-conferencing teaching: a design thinking approach. Computers \& Education, 128, $171-182$.

Verma, A., \& Singh, A. (2010). Webinar-education through digital collaboration. Journal of Emerging Technologies in Web Intelligence, 2, 131-136.

Wang, S. K., \& Hsu, H. Y. (2008). Use of the webinar tool (Elluminate) to support training: The effects of webinar-learning implementation from student-trainers' perspective. Journal of Interactive Online Learning, 7(3), 175-194.

Webinar. (2010). Merriam-webster online dictionary. Retrieved February 23, 2010, from https://www.merri am-webster.com/dictionary/webinar.

Young, C., \& Asensio, M. (2002). Looking through three I's: the pedagogic use of streaming video. In Banks, S, Goodyear, P. Hodgson, V, Connell, D. (Eds), Network Learning. Proceeding of the Third International Conference. Sheffield March. 42; 628-633.

Zhang, D., Zhou, L., Brigs, R. O., \& Nunamaker, J. F., Jr. (2006). Instructional video in e-learning: Assessing the impact of interactive video on learning effectiveness. Information and Management, 43, 15-27.

Publisher's Note Springer Nature remains neutral with regard to jurisdictional claims in published maps and institutional affiliations. 